\title{
Teores de proteína bruta no concentrado e níveis de suplementação para vacas leiteiras em pastagens de capim-braquiária cv. Marandu no período da seca ${ }^{1}$
}

\section{Joabe Jobson de Oliveira Pimentel ${ }^{2}$, Rogério de Paula Lana ${ }^{3}$, Décio de Souza Graça ${ }^{4}$, Leovegildo Lopes de Matos ${ }^{5}$, Rafael Monteiro Araújo Teixeira ${ }^{6}$}

\footnotetext{
1 Projeto parcialmente financiado pela FAPEMIG/CNPq.

2 Doutorando do Programa de Pós-graduação em Zootecnia - UFVIViçosa-MG

3 Departamento de Zootecnia - UFV/Viçosa-MG. Bolsista 1B do CNPq.

${ }^{4}$ Departamento de Zootecnia - UFMG/Belo Horizonte. Bolsista do CNPq

${ }^{5}$ Centro Nacional de Pesquisas em Gado de Leite - EMBRAPA/Coronel Pacheco.

${ }^{6}$ Doutorando em Zootecnia/UFV.
}

RESUMO - Avaliou-se a resposta de 40 vacas meio-sangue Holandês/Zebu em pastagem de Brachiaria brizantha à suplementação com concentrados contendo diferentes teores de proteína bruta. Além da pastagem, foram fornecidos diariamente $5,0 \mathrm{~kg}$ de cana-de-açúcar por animal. Utilizou-se como testemunha o fornecimento exclusivo de $200 \mathrm{~g}$ de suplemento mineral contendo $10 \%$ de fósforo. Foram comparados três concentrados contendo 50,0; 28,6 e $20 \%$ de proteína bruta na matéria natural, fornecidos nas quantidades de 2,0; 3,5 e 5,0 kg/vaca/dia. O delineamento experimental utilizado fo em blocos casualizados com dez repetições. Os suplementos foram fornecidos em duas porções diárias, após as ordenhas, em baias individuais. Após a ordenha e suplementação matinal, as 40 vacas foram mantidas no pasto até a ordenha da tarde. A cada 21 dias pós-parto, até os 84 dias, foram feitas avaliações da produção de leite, do peso vivo e do escore corporal. A maior produção de leite ocorreu aos 63 dias pós-parto, quando foram fornecidos 3,5 kg de concentrado. Como resposta produtiva, foram obtidos valores de 1,04; 1,20; e 0,63 kg de leite por $\mathrm{kg}$ de concentrado, respectivamente, para o fornecimento de 2,0; 3,5 e 5,0 kg, em relação ao controle. Os animais do grupo controle tiveram maior perda de peso vivo e de escore corporal, enquanto entre os demais não houve diferença.

Palavras-chave: desempenho, leite, pastagem, vaca

\section{Crude protein contents in the concentrate ration and levels of supplementation for dairy cows grazing on brachiaria grass cv. Marandu during the dry season}

\begin{abstract}
It was evaluated the response of 40 Holstein/Zebu crossbred cows grazing on Brachiaria brizantha pasture to supplementation with concentrates containing different contents of crude protein. In addition to the pasture, $5.0 \mathrm{~kg}$ of sugar cane per animal was supplied daily. For control, it was used $200 \mathrm{~g}$ mineral supplement with $10 \%$ of phosphorous exclusively. Three concentrates containing 50.0; 28.6 and 20.0\% of crude protein in natural matter, supplied at the quantities of $2.0 ; 3.5$ and $5.0 \mathrm{~kg} / \mathrm{cow} /$ day were compared. A randomized blocks design with 10 replicates was utilized. The supplements were given in two daily portions, after milking, in individual pens. After milking and morning supplementation, the forty cows were kept on pasture until the afternoon milking. At every 21 days after calving, until day 84, evaluations on milk productions, body weight and body condition score were made. The greatest milk production occurred 63 days after calving, when $3.5 \mathrm{~kg}$ of concentrate was supplied. As productive response, it was obtained values of $1.04 ; 1.20$; and $0.63 \mathrm{~kg}$ of milk per $\mathrm{kg}$ of concentrate, respectively, for supply of $2.0 ; 3.5$ and $5.0 \mathrm{~kg}$ regarded to the control. The animals in the control group had greater loss of body weight and body condition score, whereas there were no other differences among the other animals.
\end{abstract}

Key Words: cow, milk, pasture, performance

\section{Introdução}

O crescimento da produção de leite no Brasil nos últimos anos têm sido bastante significativo, enquanto o consumo interno tem se expandido em ritmo mais lento (Anualpec, 2008).

A maior oferta de leite tem provocado redução no preço pago aos produtores brasileiros, portanto, para que os 
sistemas de produção sejam sustentáveis, tem sido necessário produzir leite a baixo custo. Devido ao alto custo dos volumosos conservados, a utilização de pastagens como base para a alimentação animal nas condições brasileiras constitui-se na alternativa mais viável para maior lucratividade da atividade leiteira (Matos, 1995; Vilela et al., 1996). Com pastagens bem manejadas, é possível atingir produções de leite de 12 a 14 kg/vaca/dia sem o uso de concentrados no período das chuvas (Deresz, 1994; Alvim et al., 1997), o que não poderia ser alcançado para pastagens vedadas para uso na seca.

Em pesquisas com suplementação a vacas leiteiras, têm sido utilizadas rações concentradas com 20 a 24\% de proteína bruta. O nível de energia, por outro lado, varia de 70 a $75 \%$ de NDT. Quando essas formulações são utilizadas para balancear dietas formuladas para atender às exigências nutricionais de vacas leiteiras com produção entre 15 e 20 kg por dia, calculados de acordo com NRC (2001) ou Lana (2007), sempre ocorre sobra de energia no balanceamento final da dieta quando o volumoso utilizado são pastagens ou silagens de milho ou de sorgo.

Ao simular o uso de concentrados com mais alta concentração de PB e minerais e com menor concentração de NDT, no balanceamento de dietas com volumosos tropicais, poderiam ser utilizadas menores quantidades de concentrado para atender aos requerimentos de $\mathrm{PB}$ e minerais sem deixar de atender aos requerimentos de energia. Reduzindo a quantidade de concentrados, o produtor de leite pode obter melhor rentabilidade com menor emissão de dejetos no meio ambiente.

Objetivou-se com este trabalho verificar a resposta de vacas leiteiras em pastagens de Brachiaria brizantha a quatro níveis de suplementação proteica no concentrado.

\section{Material e Métodos}

O experimento foi conduzido na fazenda Estância Santa Maria, município de Carlos Chagas, região do Vale do Mucuri, nordeste de Minas Gerais, entre os meses de abril a setembro de 2006. O delineamento experimental foi em blocos ao acaso com 10 repetições por nível proteico. Os animais foram alocados nos grupos conforme ocorriam os partos, formando blocos de acordo com a data do parto. Ao todo foram formados dez blocos com quatro animais cada.

Os animais receberam os suplementos a partir de 30 dias antes do parto com 2,0 kg de concentrado contendo $20 \%$ de proteína bruta para adaptação às condições experimentais e ao consumo de concentrados, já que este não fazia parte do manejo dos animais da fazenda.
Tabela 1 - Composição percentual dos ingredientes utilizados nos suplementos

\begin{tabular}{lcccc}
\hline Ingrediente & \multicolumn{3}{c}{ Suplemento } & (kg/animal/dia) \\
\cline { 2 - 5 } & 0,2 & 2,0 & 3,5 & 5,0 \\
\hline Milho moído & & 29,0 & 69,2 & 85,0 \\
Farelo de soja & 51,0 & 19,4 & 7,0 \\
Ureia/sulfato de amônio (9/1) $^{\text {Mistura mineral }}{ }^{1}$ & & 10,0 & 5,7 & 4,0 \\
\hline
\end{tabular}

${ }^{1}$ Níveis de garantia (por kg): cálcio - $175 \mathrm{~g}$; fósforo - $100 \mathrm{~g}$; sódio - $114 \mathrm{~g}$ selênio - 15 g; magnésio - 15 g; zinco - 6.004 mg; manganês - $1.250 \mathrm{mg}$ cobre - 1.875; iodo - $180 \mathrm{mg}$; cobalto - $125 \mathrm{mg}$; selênio - $30 \mathrm{mg}$; flúor (máximo) $1.000 \mathrm{mg}$.

Como volumoso os animais tiveram à sua disposição pastagens de Brachiaria brizantha e $5 \mathrm{~kg}$ de cana-deaçúcar por animal/dia. Como testemunha foi fornecido sal mineral. Foram avaliadas três outras formas de suplementação, com fornecimento de concentrado com diferentes teores de proteína bruta (Tabela 1), nas quantidades de 0,$2 ; 2,0 ; 3,5$ e $5,0 \mathrm{~kg} / \mathrm{dia}$, com 0,0; 50,0; 28,6; e 20\% de proteína respectivamente. Os concentrados foram formulados utilizando milho moído, farelo de soja, ureia/ sulfato de amônio (9:1) e mistura mineral. O suplemento mineral fornecido como controle e utilizado na formulação dos concentrados consistiu de um produto comercial pronto para uso de uma fábrica de suplementos local (Sopec 100). Utilizou-se a mesma mistura mineral para todos os grupos, de modo que as quantidades de minerais suplementados fossem as mesmas. Os concentrados foram balanceados para que o consumo de ureia também fosse o mesmo nos grupos em que foram fornecidos concentrados. A combinação do teor de proteína com a quantidade de concentrado visou proporcionar o mesmo consumo de proteína bruta (1,0 kg/vaca/dia) do concentrado nos níveis de 2,0; 3,5 e 5,0 kg/vaca/dia.

Os concentrados foram fornecidos em duas porções diárias, metade depois de cada ordenha. Para auxiliar no consumo do sal mineral e dos suplementos com alto teor de proteína, menos palatáveis devido à alta concentração de ureia, foram utilizados $2,5 \mathrm{~kg}$ de cana-de-açúcar picada imediatamente antes do arraçoamento, misturada aos concentrados em cada manejo, totalizando 5,0 kg/dia.

Para o manejo individual dos animais, foram construídas 40 baias de $4 \times 5 \mathrm{~m}(\mathrm{~L} \times \mathrm{C})$, providas de cocho comedouro. Após o consumo dos suplementos, os animais foram mantidos em mesmo piquete no período entre as ordenhas e durante a noite.

Foi utilizada pastagem de Brachiaria brizantha, dividida em nove piquetes de tamanhos variados, somando aproximadamente 35 hectares de área total. As pastagens foram vedadas no mês de janeiro (para pastejo em abril, maio e junho) e em fevereiro (para pastejo em julho, agosto e 
setembro). Para avaliação do valor nutricional da pastagem, utilizou-se o método amostragem por pastejo simulado, com observação do hábito de pastejo dos animais no piquete durante três dias antes da pesagem de leite, formando-se em seguida uma amostra composta. A disponibilidade de forragem foi medida com o auxílio de um quadrado de 1,0 × $1,0 \mathrm{~m}$, feito com vergalhão de ferro, que foi lançado por 10 vezes na área do piquete. Toda a forragem contida dentro do quadro foi cortada a uma altura de $10 \mathrm{~cm}$, pesada e os pesos registrados em planilha própria.

Os animais foram pesados e avaliados quanto ao escore corporal ao parto e a cada 21 dias após o parto foram feitas avaliações de peso vivo, produção de leite, escore corporal. Nesses períodos, efetuou-se também a coleta de amostras da pastagem, da cana-de-açúcar e dos suplementos. Amostras do leite foram coletadas aos 42 dias pós-parto e congeladas para posteriores análises. Os valores de peso vivo e produções de leite foram obtidos pela média obtida de avaliações em dois dias consecutivos. A pesagem dos animais foi feita logo após a ordenha da manhã antes do fornecimento da alimentação.

A produção de leite corrigida para $4 \%$ de gordura foi obtida pela fórmula: $\mathrm{PLC}=(0,4 \times \mathrm{PL})+(15 \times(\mathrm{PL} \times \mathrm{GOR})$, segundo o NRC (2001), em que PLC = produção de leite corrigida para $4 \%$ de gordura, em kg por dia; $\mathrm{PL}$ = produção de leite, em kg/dia; GOR = produção de gordura em kg por dia (GOR = PL ×\%GOR), em que \%GOR é a porcentagem de gordura do leite.

As datas para coleta de dados foram calculadas para cada bloco a partir da data média do parto das quatro vacas que compunham cada bloco. Assim, as coletas de dados e amostras aos 21, 42, 63 e 84 dias pós-parto ocorriam em datas diferentes para cada grupo de quatro animais que faziam parte de cada bloco.

Aos 31 dias pós-parto, iniciou-se o fornecimento de óxido crômico para estimativa do consumo de pasto. Óxido crômico (10 g) foi fornecido em cartuchos de papel, após as ordenhas da manhã e da tarde, com auxílio de uma sonda esofagiana (Hopper et al., 1978). A partir do sexto dia após o início do fornecimento do óxido crômico, iniciou-se a coleta de amostras de fezes diretamente da ampola retal durante as ordenhas da manhã e da tarde, por quatro dias consecutivos. As amostras foram compostas por animal e mantidas congeladas até as análises laboratoriais. Como indicador interno foi utilizada a fibra em detergente neutro indigestível FDNi, por permitir melhor estimativa da excreção fecal (Berchielli et al., 2000; Detmann et al., 2001; Barros et al., 2007).

Ao término do experimento, as amostras de pasto, da cana-de-açúcar, dos suplementos e das fezes foram descongeladas, pré-secas em estufa de ventilação forçada a $60^{\circ} \mathrm{C}$ durante 72 a 96 horas e, posteriormente, trituradas em moinho de facas com peneira de poros de $2 \mathrm{~mm}$. O preparo das amostras (alimento fornecido, sobras e fezes) e as análises de matéria seca (MS), matéria orgânica (MO), matéria mineral $(\mathrm{MM})$, compostos nitrogenados $(\mathrm{N})$, extrato etéreo (EE), fibra em detergente neutro (FDN) e fibra em detergente ácido (FDA) foi feito segundo Silva \& Queiroz (2002). Nas amostras de leite, que foram previamente liofilizadas, foram feitas análises de matéria seca, proteína bruta e gordura segundo Silva \& Queiroz (2002). O teor de cromo nas fezes foi determinado segundo Williams et al. (1962) utilizando-se o espectrofotômetro de absorção atômica.

Os carboidratos totais (CT) foram calculados como: $\% \mathrm{CT}=100-(\% \mathrm{~PB}+\% \mathrm{EE}+\% \mathrm{MM})$ e os nutrientes digestíveis totais (NDT) como: NDT = PBd + 2,25EEd + CTd, segundo Sniffen et al. (1992), em que: $\mathrm{PBd}=$ proteína bruta digestível; EEd = extrato etéreo digestível; CTd = carboidratos digestíveis. Os consumos de nutrientes digestíveis totais (CNDT), em quilogramas, foram calculados segundo Sniffen et al. (1992), pela equação: $C N D T=(P B$ ingerida $-\mathrm{PB}$ fecal) + 2,25 (EEingerido $-\mathrm{EE}$ fecal) $+(\mathrm{CT}$ ingerido $-\mathrm{CT}$ fecal) e NDT $(\%)=($ consumo de NDT/ consumo de MS) $\times 100$.

Para determinação da fibra em detergente neutro indigestível, utilizaram-se alíquotas de aproximadamente 1,0 g das amostras de alimentos, sobras e fezes, acondicionadas, em duplicata, em sacos de náilon de $5,5 \times 5,5 \mathrm{~cm}$, com porosidade de $50 \mathrm{ìm}$, previamente pesados e identificados. Os sacos foram selados a quente e incubados durante 144 horas no rúmen (Berchielli et al., 2000; Detmann et al., 2007) de um bovino adulto alimentado em pastagem de Brachiaria decumbens e $2,0 \mathrm{~kg}$ de concentrado (20\% PB) por dia. Posteriormente, foram retirados, lavados até completo clareamento da água, levados a estufa de ventilação forçada a $60^{\circ} \mathrm{C}$ por 72 horas e submetidos à secagem em estufa a $105^{\circ} \mathrm{C}$ por 1 hora. Em seguida, foram retirados, esfriados em dessecador e pesados para determinação da concentração de MSi. Parte das amostras, após incubação, foi submetida à fervura em detergente neutro (Goering \& Van Soest, 1970), por 1 hora, lavada com água quente e acetona, seca e pesada, pelo mesmo procedimento, para determinação da FDNi.

No cálculo da produção fecal, utilizou-se a fórmula: $\mathrm{PF}=$ indicador administrado (g)/concentração do indicador nas fezes (\%). Os dados obtidos foram submetidos à análise de variância utilizando-se o programa de análises estatísticas Minitab ${ }^{\circledR}$. Para análise estatística e comparação entre médias, utilizou-se o método de análise de contrastes ortogonais completos, segundo Steel \& Torrie (1960) (Tabela 2). 
Tabela 2 - Modelo para análise de contrastes ortogonais completos (Steel \& Torrie, 1960)

\begin{tabular}{|c|c|c|c|c|}
\hline & \multicolumn{4}{|c|}{ Suplemento (kg/animal/dia) } \\
\hline Contraste & 0,2 & 2,0 & 3,5 & 5,0 \\
\hline Concentrado & -3 & 1 & 1 & 1 \\
\hline Linear & 0 & -1 & 0 & 1 \\
\hline Quadrático & 0 & 1 & -2 & 1 \\
\hline
\end{tabular}

\section{Resultados e Discussão}

As concentrações de proteína bruta dos suplementos (Tabela 3) ficaram muito próximas dos valores calculados no balanceamento prévio. O teor médio de proteína bruta do capim Brachiaria brizantha foi superior ao esperado para o período da seca. Entretanto, a boa oferta de forragem, ainda com muitas folhas verdes, permitiu a seleção dessa fração pelos animais, refletida pelo método de amostragem de pastejo simulado. Pela análise de extrusa, Euclides et al. (2000) observaram que, mesmo com a baixa disponibilidade de MS nas pastagens, durante todo o ano, a participação de folhas na dieta selecionada pelo animal foi superior a $84 \%$ e a quantidade de material morto correspondeu a apenas pequena proporção da dieta, variando de 5 a $10 \%$. Nicodemo et al. (2004) encontraram 5,3 a 10,4\% de PB em amostras de pastagem de Brachiaria brizanta coletada nos meses de junho e julho em três anos consecutivos.

Costa et al. (2007) encontraram teores de MS, PB, FDN e FDA de 26,6; 8,26; 70,82; e 36,0\%, respectivamente, quando avaliaram a Brachiaria brizantha cultivar MG-5 com 60 dias de rebrota. Esses autores observaram que o valor nutritivo reduziu com o avanço da maturidade da planta. Neste estudo, a pastagem ficou vedada por 3 a 4 meses antes de ser utilizada pelos animais. Os teores de nutrientes encontrados na cana-de-açúcar estão de acordo com aqueles determinados por Fernandes et al. (2003) para algumas variedades de ciclo precoce e intermediário.
As concentrações de proteína bruta das dietas consumidas (Tabela 4) estão abaixo das recomendações de Lana (2005) em pesquisa com simulações com os pesos, as produções e teores de gordura encontrados para cada nível proteico. Por outro lado, as concentrações de NDT encontradas nos níveis de 2,0; 3,5 e 5,0 kg de suplemento foram mais altas.

As disponibilidades de matéria seca encontradas nesta pesquisa (Tabela 5) são semelhantes aos valores observados por Euclides et al. (2000) para o período da seca em estudo no qual avaliaram o consumo de matéria seca em novilhos pastejando Brachiaria brizantha e mais altos que o valor crítico sugerido por Gomide (1993), de $2.500 \mathrm{~kg}$ MS/ha, e pelo NRC (2000), de $2.250 \mathrm{~kg}$ MS/ha, para reduzir o consumo voluntário de matéria seca de animais em pastejo, quando da entrada no pasto.

Os consumos de MS, PB e NDT e os consumos em porcentagem do peso vivo de MS e FDN foram menores quando os animais receberam apenas sal mineral em relação à suplementação com concentrados (Tabela 6), mas não houve diferença entre os três níveis de concentrado. Bargo et al. (2003) compilaram dados de mais de 20 experimentos internacionais e demonstraram que o aumento no fornecimento de concentrado eleva o consumo total de matéria seca em vacas leiteiras em pastejo. O baixo consumo de matéria seca observado quando a pastagem foi suplementada apenas com sal mineral pode ser explicado pelo baixo teor de proteína bruta da dieta consumida. Milford \& Minson, em 1965, citados por Martin et al. (1981), afirmaram que o consumo de forragem de baixa qualidade é aparentemente limitado pela insuficiência de nitrogênio aos microrganismos do rúmen.

O consumo de pasto foi maior nos grupos que receberam 2,0 e 3,5 kg de suplemento em relação àqueles que receberam apenas sal mineral, o que revela efeito associativo positivo da suplementação no consumo do pasto. A suplementação proteica de volumosos com baixo

Tabela 3 - Composição bromatológica dos concentrados, da pastagem e da cana-de-açúcar (\% MS)

\begin{tabular}{|c|c|c|c|c|c|c|}
\hline \multirow[b]{2}{*}{ Item } & \multicolumn{4}{|c|}{ Suplemento (kg/animal/dia) } & \multirow[t]{2}{*}{ Capim-braquiária } & \multirow[t]{2}{*}{ Cana-de-açúcar } \\
\hline & 0,2 & 2,0 & 3,5 & 5,0 & & \\
\hline Matéria seca ${ }^{2}$ & 98,3 & 88,2 & 86,5 & 84,7 & 36,1 & 28,4 \\
\hline Proteína bruta & 0,0 & 50,3 & 30,1 & 21,2 & 7,8 & 2,77 \\
\hline Extrato etéreo & 0,0 & 1,73 & 1,85 & 2,02 & 2,90 & 0,72 \\
\hline Carboidratos totais & 0,0 & 33,1 & 59,3 & 70,5 & 83,6 & 94,8 \\
\hline Matéria mineral & 99,2 & 14,9 & 8,7 & 6,2 & 5,8 & 1,7 \\
\hline
\end{tabular}

\footnotetext{
${ }^{2}$ Em porcentagem da matéria natural.
} 
Tabela 4 - Composição bromatológica das dietas (\%MS)

\begin{tabular}{lcccr}
\hline & \multicolumn{4}{c}{ Suplemento $(\mathrm{kg} /$ animal/dia) } \\
\cline { 2 - 5 } Item & 0,2 & 2,0 & 3,5 & 5,0 \\
\hline Matéria seca1 & 35,3 & 37,8 & 39,7 & 41,8 \\
Matéria orgânica & 93,0 & 93,5 & 94,0 & 94,5 \\
Proteína bruta & 6,91 & 12,3 & 11,7 & 11,0 \\
Extrato etéreo & 2,56 & 2,55 & 2,49 & 2,45 \\
Carboidratos totais & 83,53 & 78,61 & 79,83 & 80,98 \\
Fibra em detergente neutro & 68,36 & 63,11 & 58,63 & 53,67 \\
Fibra em detergente ácido & 39,19 & 35,69 & 32,85 & 29,61 \\
Matéria mineral & 6,99 & 6,50 & 5,99 & 5,54 \\
Nutrientes digestíveis totais & 52,8 & 60,7 & 63,5 & 65,1 \\
\hline${ }^{1}$ Em porcentagem da matéria natural. & & & &
\end{tabular}

Tabela 5 - Disponibilidade de MS da pastagem de Brachiaria brizantha em kg de MS por hectare em cada período de coleta de dados

\begin{tabular}{lcccc}
\hline & \multicolumn{4}{c}{ Período de coleta } \\
\cline { 2 - 5 } Disponibilidade de MS & 21 & 42 & 63 & 84 \\
\hline
\end{tabular}

teor de proteína bruta aumenta o consumo de matéria seca (Pimentel et al., 1998). Lopes et al. (2004) verificaram aumento $(\mathrm{P}<0,05)$ no consumo de matéria seca do volumoso em vacas mestiças Holandês $\times$ Zebu com produção média de leite entre 11 a $12 \mathrm{~kg} /$ dia recebendo 2,0 kg de MS de concentrado. Entretanto, o consumo de pasto decresceu linearmente com o aumento de 2,0 para 5,0 kg na quantidade de suplemento.

A queda no consumo de volumoso quando se suplementa com concentrados é conhecida como taxa de substituição. Quanto mais alta for a taxa de substituição de volumosos por concentrados, maior a quantidade de concentrado fornecida (Bargo et al., 2003). Lima et al. (2001) observaram que o fornecimento de $3 \mathrm{~kg}$ de concentrado por vaca/dia provocou redução de $24,5 \%$ no consumo de capim, quando se considerou a ingestão total de matéria seca de 33,3\% quando se considerou o consumo em relação ao peso vivo, o que comprova efeito de substituição do consumo de pastagem pelo concentrado. Por outro lado,
Sousa et al. (2008) verificaram que o consumo de pastagem foi maior quando a suplementação com concentrados passou de 4 para $8 \mathrm{~kg} / \mathrm{vaca} / \mathrm{dia}$.

$\mathrm{O}$ teor de FDN encontrado para a pastagem utilizada neste estudo excede ao limite de 55-60\% na MS, acima do qual o consumo de pasto é comprometido (Van Soest, 1965; Mertens, 1987). Entretanto, os consumos de FDN em porcentagem do peso vivo estão muito acima do valor de 1,2\% citado por Mertens (1994) para obtenção de máxima produção de leite. Avaliando o consumo de vacas leiteiras em pastagem de capim-tanzânia, Lima et al. (2001) também estimaram o consumo de FDN acima de 1,2\% do peso vivo. Euclides et al. (2001) encontraram consumos de FDN entre 1,46 e 1,82\% do peso vivo para pastagem de Brachiaria brizantha. Sousa et al. (2008) encontraram aumento no consumo de FDN quando aumentaram a quantidade de concentrado fornecido. Na literatura nacional, a média geral para o consumo de FDN em relação ao peso vivo foi de 1,6\% (Sousa et al., 2008).

Os coeficientes de digestibilidade da MS, MO, PB, carboidratos totais e os teores de NDT apresentaram crescimento linear, sendo os maiores valores verificados para os maiores níveis de suplementação (Tabela 7). Os coeficientes de digestibilidade do EE e FDN foram mais altos quando fornecida suplementação com concentrados e não houve diferença entre as três formas de suplementação testadas. Os baixos coeficientes de digestibilidade e de nutrientes digestíveis totais da dieta com uso exclusivo de suplemento mineral refletem a baixa qualidade da pastagem disponível no período da seca.

A produção de leite foi menor quando as vacas foram suplementadas apenas com sal mineral (Tabela 8). Nas medições realizadas aos 21, 42 e 84 dias pós-parto, a produção de leite não diferiu entre as formas de suplementação com concentrados. Entretanto, para produção de leite aos 63 dias, o fornecimento de $3,5 \mathrm{~kg}$ de concentrado proporcionou maior produção em relação ao fornecimento de 2,0 ou 5,0 kg.

Tabela 6 - Consumos de nutrientes com respectivos erros-padrão

\begin{tabular}{|c|c|c|c|c|c|c|c|c|}
\hline & \multicolumn{4}{|c|}{ Suplemento (kg/animal/dia) } & \multicolumn{3}{|c|}{ Significância $(P=)$} & \multirow[b]{2}{*}{ EP } \\
\hline & 0,2 & 2,0 & 3,5 & 5,0 & Suplemento & Linear & Quadrático & \\
\hline \multicolumn{9}{|c|}{ Consumos em kg/dia } \\
\hline Volumoso em MS & 10,6 & 12,9 & 12,3 & 10,8 & 0,05 & 0,02 & ns & 0,588 \\
\hline Proteína bruta & 0,74 & 1,81 & 1,79 & 1,66 & 0,001 & 0,02 & ns & 0,045 \\
\hline Nutrientes digestíveis totais & 5,7 & 8,95 & 9,71 & 9,80 & 0,001 & ns & ns & 0,412 \\
\hline Fibra em detergente neutro & 1,51 & 1,80 & 1,82 & 1,61 & 0,004 & 0,041 & ns & 0,064 \\
\hline
\end{tabular}


Tabela 7 - Coeficientes de digestibilidade dos nutrientes e teores de nutrientes digestíveis totais, com respectivos erros-padrão

\begin{tabular}{|c|c|c|c|c|c|c|c|c|}
\hline & \multicolumn{4}{|c|}{ Suplemento (kg/animal/dia) } & \multicolumn{3}{|c|}{ Significância (P =) } & \multirow[b]{2}{*}{ EP } \\
\hline & 0,2 & 2,0 & 3,5 & 5,0 & Suplemento & Linear & Quadrático & \\
\hline Matéria seca & 49,84 & 58,36 & 60,57 & 62,26 & 0,001 & 0,003 & ns & 0,851 \\
\hline Matéria orgânica & 55,17 & 62,93 & 65,23 & 66,85 & 0,001 & 0,001 & ns & 0,757 \\
\hline Proteína bruta & 48,16 & 72,38 & 70,68 & 67,54 & 0,001 & 0,016 & ns & 1,333 \\
\hline Extrato etéreo & 48,20 & 58,99 & 59,58 & 62,35 & 0,001 & ns & ns & 1,664 \\
\hline Fibra em detergente neutro & 46,96 & 51,84 & 51,53 & 51,82 & 0,003 & ns & ns & 1,267 \\
\hline Carboidratos totais & 55,96 & 61,49 & 64,58 & 66,89 & 0,001 & 0,001 & ns & 0,832 \\
\hline Nutrientes digestíveis totais & 52,85 & 60,70 & 63,48 & 65,06 & 0,001 & 0,001 & ns & 0,734 \\
\hline
\end{tabular}

Graus de liberdade do resíduo $=27$

Tabela 8 - Produção e composição do leite em cada nível de suplementação

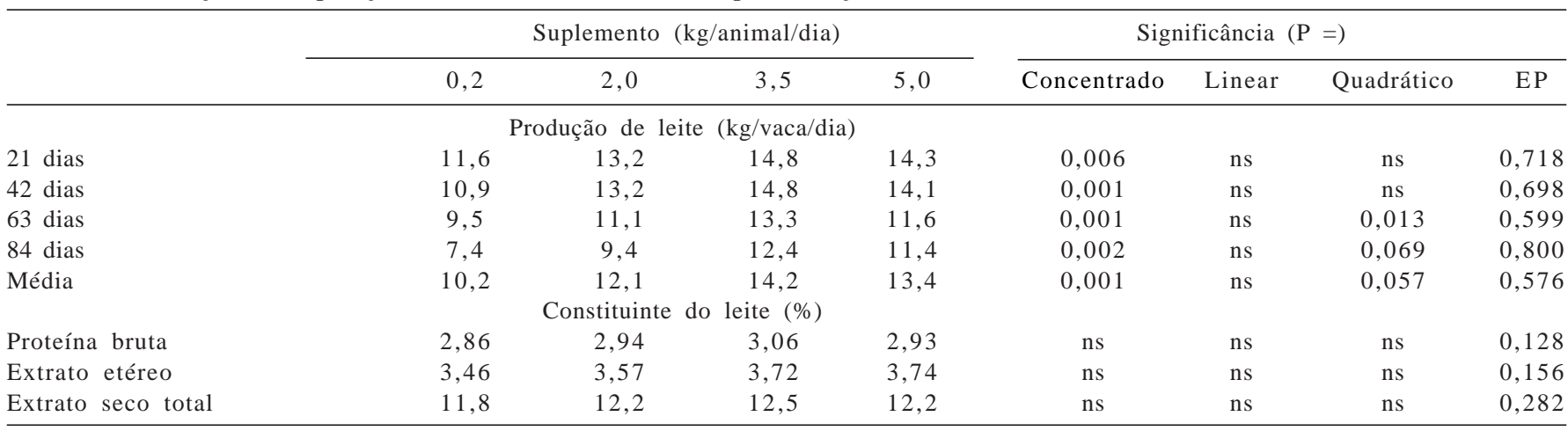

Graus de liberdade do resíduo $=27$.

As médias de produção de leite foram maiores quando se utilizou suplementação com concentrados em relação à suplementação apenas com sal mineral. Gomide et al. (2001) avaliaram duas ofertas de forragem de Brachiaria decumbens com suplementação de $2,0 \mathrm{~kg}$ de um concentrado contendo $20 \%$ de PB e $75 \%$ de NDT e encontraram produções de leite entre 10 e 11,6 kg/vaca/dia. Vilela et al. (2007) encontraram produções em leite de $15,5 \mathrm{~kg}$ por dia para vacas no terço médio da lactação que consumiam pastagem de capim coast-cross com suplementação de concentrado (3 kg/dia).

As respostas produtivas variaram de 0,450 a $1,510 \mathrm{~kg}$ de leite por kg de concentrado acrescentado e foram maiores nos períodos posteriores, provavelmente devido ao avanço na maturidade do pasto (Tabela 9). Gomide et al. (1993) relataram respostas produtivas variando de 0,5 a $1,5 \mathrm{~kg}$ de $\mathrm{kg}$ de leite por $\mathrm{kg}$ de para vacas em pastagens.

Tabela 9 - Resposta em kg de leite por kg de concentrado em cada forma de suplementação

\begin{tabular}{lccc}
\hline & \multicolumn{3}{c}{ Suplemento (kg/animal/dia) } \\
\cline { 2 - 4 } & 2,0 & 3,5 & 5,0 \\
\hline 21 dias & 0,98 & 0,97 & 0,56 \\
42 dias & 1,25 & 1,18 & 0,66 \\
63 dias & 0,88 & 1,17 & 0,45 \\
84 dias & 1,13 & 1,51 & 0,83 \\
Média & 1,04 & 1,20 & 0,63 \\
\hline
\end{tabular}

De acordo com Vilela et al. (1980), a resposta produtiva de vacas leiteiras em pastagem à suplementação varia de 0,50 a $0,90 \mathrm{~kg}$ de leite por $\mathrm{kg}$ de concentrado no período de chuva e de 0,80 a 0,95 no período de seca. Deresz \& Matos (1996) encontraram resposta de 0,5 quilo de leite por quilo de concentrado enquanto Alvim et al. (1997) observaram resposta de 1,0 quilo de leite por quilo de concentrado. Aumento de $1,2 \mathrm{~kg}$ de leite por $\mathrm{kg}$ de concentrado foi observado por Vilela et al. (2007) quando compararam o fornecimento de 3 ou $6 \mathrm{~kg}$ de concentrado por dia para vacas em pastagem de Coast-cross. Maior resposta foi relatada por Lima et al. (2001) que encontraram aumento de $1,82 \mathrm{~kg}$ de leite para cada kg de concentrado fornecido.

A formulação utilizada com fornecimento de $5,0 \mathrm{~kg}$ (concentrado com 20\% de PB), que representa a formulação padrão comercializada no Brasil para os produtores de leite e utilizada em grande parte das pesquisas com vacas leiteiras, proporcionou menor resposta produtiva por $\mathrm{kg}$ de suplemento utilizado $(0,63 \mathrm{~kg}$ de leite por $\mathrm{kg}$ de concentrado), enquanto aquela com fornecimento de $3,5 \mathrm{~kg}$ (concentrado com 28,6\% de PB) promoveu a melhor resposta produtiva, com $1,20 \mathrm{~kg}$ de leite por $\mathrm{kg}$ de concentrado.

Os animais submetidos ao consumo exclusivo de pasto e sal mineral sofreram maior perda de peso e de escore 
corporal em relação aos animais que receberam suplementação com concentrados, que não diferiram entre si (Tabela 10).

As variações de peso vivo e de escore corporal foram mais expressivas para os animais que receberam apenas suplemento mineral, não havendo diferença significativa para os animais que receberam suplementação com concentrados. A mobilização de reservas para produção de leite no início da lactação leva o animal a uma perda de peso nesta fase, o que é um aspecto normal da fisiologia da vaca leiteira. Todavia, perdas de peso excessivas no início da lactação podem prejudicar a eficiência reprodutiva, retardar o aparecimento dos cios e aumentar o intervalo entre partos. A perda de peso foi em média de $500 \mathrm{~g} /$ dia quando os animais receberam suplementação com concentrados, o que está dentro de valores normais para essa fase da lactação e provavelmente não comprometeria a reprodução dos animais.

Tabela 10 - Variações de peso vivo e de escore corporal aos 21, 42, 63 e 84 dias pós-parto

\begin{tabular}{|c|c|c|c|c|c|c|c|c|}
\hline \multirow[b]{2}{*}{ Item } & \multicolumn{4}{|c|}{ Suplemento (kg/animal/dia) } & \multicolumn{3}{|c|}{ Significância $(P=)$} & \multirow[b]{2}{*}{ EP } \\
\hline & 0,2 & 2,0 & 3,5 & 5,0 & Concentrado & Linear & Quadrático & \\
\hline \multicolumn{9}{|c|}{ Variação de peso vivo } \\
\hline 42 dias & $-0,83$ & $-0,28$ & $-0,57$ & $-0,52$ & ns & ns & ns & 0,261 \\
\hline 63 dias & $-1,79$ & $-1,04$ & $-0,92$ & $-0,77$ & 0,006 & ns & ns & 0,249 \\
\hline 84 dias & $-0,62$ & $-0,62$ & $-0,43$ & $-0,29$ & ns & ns & ns & 0,231 \\
\hline 21 dias & $-0,3$ & $-0,3$ & $-0,3$ & $-0,3$ & ns & ns & ns & 0,084 \\
\hline 42 dias & $-0,2$ & 0,0 & 0,0 & 0,0 & ns & ns & ns & 0,111 \\
\hline 63 dias & $-0,4$ & $-0,1$ & $-0,0$ & 0,1 & 0,003 & ns & ns & 0,092 \\
\hline 84 dias & $-0,3$ & 0,2 & 0,1 & $-0,1$ & 0,003 & 0,031 & ns & 0,087 \\
\hline Média & $-1,12$ & $-0,28$ & $-0,29$ & $-0,27$ & 0,001 & ns & ns & 0,035 \\
\hline
\end{tabular}

Graus de liberdade do resíduo $=27$.

\section{Conclusões}

Concentrados com 28,6\% de proteína bruta proporcionam maior produção de leite e melhor resposta produtiva em vacas leiteiras no período da seca em relação à fórmula tradicional com $20 \%$ de proteína bruta e ao fornecimento de concentrado com $50 \%$ de proteína bruta. $\mathrm{O}$ teor de proteína do concentrado fornecido a vacas leiteiras de produção moderada (até $15 \mathrm{~kg}$ de leite) em pasto de braquiária no período de transição águas/seca deve ser maior que o de rações comerciais.

\section{Referências}

ALVIM, M.J.; VILELA, D.; LOPES, R.S. Efeitos de dois níveis de concentrado sobre a produção de leite de vacas da raça Holandesa em pastagem de Coast-cross (Cynodon dactylon (L.) Pers). Revista Brasileira de Zootecnia, v.26, n.5, p.967-975, 1997. ANUALPEC 2008. Anuário Estatístico da Pecuária Brasileira. São Paulo: Argos Comunicação FNP, 2008. 380p.

BARGO, F.; MULLER, L.D.; KOLVER, E.S. et al. Invited review: Production and digestion of supplemented dairy cows on pasture. Journal of Dairy Science, v.86, p.1-42, 2003.

BARROS, E.E.L.; FONTES, C.A.A.; DETMANN, E. et al. Avaliação do perfil nictemeral de excreção de indicadores internos e de óxido crômico em ensaios de digestão com ruminantes. Revista Brasileira de Zootecnia, v.36, n.6, p.2102-2108, 2007 (supl.).
BERCHIELLI, T.T.; ANDRADE, P.; FURLAN, C.L. Avaliação de indicadores internos em ensaios de digestibilidade. Revista Brasileira de Zootecnia, v.29, n.3, p.830-833, 2000.

COSTA, K.A.P.; OLIVEIRA, I.P.; FAQUIN, V. Intervalo de corte na produção de massa seca e composição químicobromatológica da Brachiaria brizantha cv MG-5. Ciência Agrotécnica Lavras, v.31, n.4, p.1197-1202, 2007.

DERESZ, F. Manejo de pastagem de capim-elefante para produção de leite e carne. In: SIMPÓSIO SOBRE CAPIM-ELEFANTE, 2., 1994, Juiz de Fora. Anais... Coronel Pacheco: Embrapa, 1994. p.116-137.

DERESZ, F.; MATOS, L.L. Influência do período de descanso da pastagem de capim-elefante na produção de leite de vacas mestiças Holandês-Zebu. In: REUNIÃO ANUAL DA SOCIEDADE BRASILEIRA DE ZOOTECNIA, 33., 1996, Fortaleza-CE. Anais... Fortaleza: Sociedade Brasileira de Zootecnia, 1996. p.166-168.

DETMANN, E.; SOUZA, A.L.; GARCIA, R. Avaliação do vício de "tempo longo" de indicadores internos em ensaio de digestão com ruminantes. Arquivos Brasileiros de Medicina Veterinária e Zootecnia, v.59, n.1, p.182-188, 2007.

DETMANN, E.; PAULINO, M.F.; ZERVOUDAKIS, J.T. et al. Cromo e indicadores internos na determinação do consumo de novilhos mestiços, suplementados, a pasto. Revista Brasileira de Zootecnia, v.30, n.5, p.1600-1609, 2001.

EUCLIDES, V.P.; CARDOSO, E.G.; MACEDO, M.C.,M et al. Consumo voluntário de Brachiaria decumbens cv. Basilisk e Brachiaria brizantha cv. Marandu sob pastejo. Revista Brasileira de Zootecnia, v.29, n.6, p.2200-2208, 2000 (supl. 2).

FERNANDES, A.M.; QUEIROZ, A.C.; PEREIRA, J.C. et al. Composição químico-bromatológica de variedades de canade-açúcar (Saccharum spp L.) com diferentes ciclos de produção (precoce e intermediário) em três idades de corte. 
Revista Brasileira de Zootecnia, v.32, n.4, p.977-985, 2003.

GOERING, H.K.; van SOEST, P.J. Forage fiber analyses. Washington: ARS-USDA, 1970. 20p. (Agriculture Handbook, 379).

GOMIDE, J.A. Produção de leite em regime de pasto. Revista Brasileira de Zootecnia, v.22, p.591-613, 1993.

GOMIDE, J.A.; WENDLING, I.J.; BRAS, S.P. et al. Consumo e produção de leite de vacas mestiças em pastagens de Brachiaria decumbens manejada sob duas ofertas diárias de forragem. Revista Brasileira de Zootecnia, v.30, p.1194-1199, 2001.

HOPPER, J.T.; HOLLOWAY, J.W.; BUTTS JUNIOR, W.T. Animal variation in chromium sesquioxide excretion patterns of grazing cows. Journal of Animal Science, v.46, n.4, p.1098-1102, 1978.

LANA, R.P. Nutrição e alimentação animal (mitos e realidades). Viçosa, MG: UFV, 2005. 344p.

LANA, R.P. Sistema Viçosa de formulação de rações. 4.ed. Viçosa, MG: UFV, 2007. 91p.

LIMA, M.L.P.; BERCHIELLI, T.T.; NOGUEIRA, J.R. Estimativa do consumo voluntário do capim-Tanzânia (Panicum maximum, Jacq. cv. Tanzânia) por vacas em lactação sob pastejo rotacionado. Revista Brasileira de Zootecnia, v.30, n.6, p.1919-1924, 2001.

LOPES, F.C.F.; AROEIRA, L.J.M.; RODRIGUEZ, N.M. et al. Efeito da suplementação e do intervalo de pastejo sobre a qualidade da forragem e consumo voluntário de vacas Holandês x Zebu em lactação em pastagem de capim-elefante. Arquivos Brasileiros de Medicina Veterinária e Zootecnia, v.56, p.355-362, 2004.

MARTIN, L.C.; AMMERMAN, C.B.; HENRY, P.R. et al. Effect of level and form of supplemental energy and nitrogen on utilization of low quality roughages by sheep. Journal of Animal Science, v.53, n.2, p.479, 1981.

MATOS, L.L. Perspectivas em alimentação e manejo de vacas em lactação. In: REUNIÃO ANUAL DA SOCIEDADE BRASILEIRA DE ZOOTECniA, 32., 1995, Brasília. Anais... Brasília: Sociedade Brasileira de Zootecnia, 1995. p.147-155.

MERTENS, D.R. Predicting intake and digestibility using mathematical models of ruminal function. Journal of Animal Science, v.64, n.5, p.1548-1558, 1987.

MERTENS, D.R. Regulation of forage intake. In: FAHEY JR., G.C. (Ed.) Forage quality, evaluation, and utilization. Wisconsin: 1994. p.450-493.

NICODEMO, M.L.F.; MORAES, S.S.; S'THIAGO, L.R.L. et al. Desempenho de vacas jovens nelore em pastagens de Brachiaria brizantha suplementadas ou não com fósforo/cálcio e ração durante a seca. Revista Brasileira de Zootecnia, v.33, n.6, p.2151-2160, 2004 (supl. 2).

NATIONAL RESEARCH COUNCIL - NRC. Nutrient requirements of beef cattle. 5. rev. ed. Washington, DC: National Academy Press, 2000. 281p.
NATIONAL RESEARCH COUNCIL - NRC. Nutrient requirements of dairy cattle. 7. rev. ed. Washington, DC: National Academy Press, 2001. 381p.

PIMENTEL, J.J.O.; SILVA, J.F.C.; VALADARES FILHO, S.C. Efeito da suplementação protéica no valor nutritivo de silagens de milho e sorgo. Revista Brasileira de Zootecnia, v.27, n.5, p.1042-1049, 1998.

SNIFFEN, C.J.; O`CONNOR, C.D.; VAN SOEST, P.J. et al. A net carbohydrate and protein system for evaluating cattle diets. II. Carbohydrate and protein availability. Journal of Animal Science, v.70, n.11, p.3562-3577, 1992.

SILVA, D.J.; QUEIROZ, A.C. Análise de alimentos: métodos químicos e biológicos. 3.ed. Viçosa, MG: Editora UFV, 2002. 235p.

SOARES, J.P.G.; BERCHIELLI, T.T.; AROEIRA, J.M. et al. Estimativas de consumo do capim-elefante (Pennisetum purpureum, Schum), fornecido picado para vacas lactantes utilizando a técnica do óxido crômico. Revista Brasileira de Zootecnia, v.33, n.3, p.811-820, 2004.

SOUSA, B.M.; SATURNINO, H.M.; BORGES, A.L.C.C. et al. Estimativa de consumo de matéria seca e de fibra em detergente neutro por vacas leiteiras sob pastejo, suplementadas com diferentes quantidades de alimento concentrado. Arquivos Brasileiros de Medicina Veterinária e Zootecnia, v.60, n.4, p.890-895, 2008.

STEEL, R.G.D.; TORRIE, J.H. Principles and procedures of statistics. New York: Mc Graw-Hill, 1960. 481p.

VAN SOEST, P.J. Nutritional ecology of the ruminants. 2.ed. Ithaca: Cornell University, 1994. 476p.

VAN SOEST, P.J. Symposium on factors influencing the voluntary intake of herbage by ruminants: voluntary intake relation to chemical composition and digestibility. Journal of Animal Science, v.24, n.3, p.834-844, 1965.

VILELA, D.; ALViM, M.J.; CAMPOS, O.F. et al. Produção de leite de vacas Holandesas em confinamento ou em pastagem de Coast-cross. Revista Brasileira de Zootecnia, v.25, n.6, p.1228-1244, 1996.

VILELA, D.; CARDOSO, R.M.; SILVA, J.F.C. et al. Efeito da suplementação concentrada sobre o consumo de nutrientes e a produção de leite, por vacas em pastagem de capim-gordura (Melinis minutiflora, Beauv). Revista Brasileira de Zootecnia, v.9, p.314-332, 1980.

VILELA, D.; FERREIRA, A.M.; RESENDE, J.C. et al. Efeito do concentrado no desempenho produtivo, reprodutivo e econômico de vacas da raça Holandesa em pastagem de Coastcross. Arquivos Brasileiros de Medicina Veterinária e Zootecnia, v.59, n.2, p.443-450, 2007.

WILLIAMS, C.H.; DAVID, D.J.; IISMAA, O. The determination of chromic oxide in faeces samples by atomic absorption spectrophotometry. Agricultural Science, v.59, p.381-385, 1962 . 